\title{
ANALIZA I UPOREDBA VARIJANTNIH RJEŠENJA GRADSKE RASKRSNICE U TUZLI
}

Zahid Bašić ${ }^{1}$

Nedim Suljić ${ }^{2}$

UDK:625.739(497.15Tuzla)

DOI:10.14415/konferencijaGFS2017.054

Rezime: Ovim radom se prezentuju varijantna rješenja gradske saobraćajnice na spoju magistralne ceste M4 i transferzale T8 u Tuzli.

Varijanta 1. je definisana na planiranoj rekonstrukciji magistralne ceste M4 na ovoj dionici, s obzirom da se ista nalazi u horizontalnoj krivini. Rekonstrukcijom magistralnog puta M4 predviđa se nadogadnja dvije saobraćajne trake $i$ korekcija elemenata horizontalne geometrije kao i nivelete u dužini od $800 \mathrm{~m}$. Transferzala T8 bi sa svijetlom visinom od 4,50 m prolazila ispod rekonstruisanog magistralnog puta M4, odnosno, magistralni put bi prelazio u nadvožnjaku preko pomenute raskrsnice. Veza denivelisanih saobraćajnica bila bi omogućena izgradnjom dvije rampe jedna uzlazno-silazna, i jedna uzlazna. Varijanta 2. je definisana na istom konceptu kao i varijanta 1, ali bez dodatnih intervencija na magistralnom putu M4 izuzev korekcija koje se odnose na obezbjeđenje neophodne visine svijetlog otvora između denivelisanih saobraćajnica. Takođe, veza T8 $i$ M4 se ostvaruje izgradnjom dvije rampe jedna silazna i jedna uzlazna kao i preko rekonstruisane dvosmjerne ceste na sjevernoj strani. Varijanta 3. je definisana kao dvotračna kružna raskrsnica sa jednotračnim ulazima/ izlazima širine 4/5 metara na magistralnom putu M4, i dvotračnim ulazima/izlazima širine 4/5 metara sa zadržavanjem središnjeg ostrva na dijelu transferzale T8 jer se na ovaj način ne ugrožava komforan poprečni profil trasnferzale. Horizontalna geometrija je projektovana kako bi se zadovoljila prohodnost mjerodavnog vozila. Kružni tok je spušten južno po pravcu transferzale T8 kako bi se dobio odgovarajući prostor, kao i da bi se izbjegli problemi sa uklapanjem u postojeće stanje tj. da se ne bi ugrozili stambeni objekti sa sjeverne strane. Radom su prikazani elementi plana i elementi profila po varijantama kao $i$ troškovi građenja uključujući i troškove eksproprijacije.

Ključne riječi: magistralni put, transferzala, raskrsnica, nadvožnjak, kružni tok

\section{UVOD}

Predmet ovog rada je rekonstrukcija raskrsnice na ukrštanju transferzale T8 i magistralnog puta M4.

\footnotetext{
${ }^{1}$ Prof.dr. Zahid Bašić, Univerzitet u Tuzli, Tihomila Markovića br.1, Tuzla, Bosna i Hercegovina, e-mail: mido_basic@hotmail.co.uk

${ }^{2}$ Prof.dr. Nedim Suljić, Univerzitet u Tuzli, Tihomila Markovića br.1, Tuzla, Bosna i Hercegovina
} 
Izvršena je analiza potencijalnih rješenja koja podrazumijevaju rekonstrukciju predmetne raskrsnice u cilju povećanja nivoa bezbijednosti nivoa usluge i integrisanja sa već postojećim i planiranim rješenjima shodno razvojnim konceptima Grada Tuzle. [1] [4] Obzirom da se radi o rekonstrukciji postojeće trokrake raskrsnice, što predstavlja zahtjevniji tehnički poduhvat, za primijenjene vrijante prije svega, sagledani su prostorni uslovi postojećeg stanja.

Trokraka raskrsnica u postojećem stanju je regulisana vertikalnom, horizontalnom i svjetlosnom signalizacijom u pogledu saobraćajnog uređenja.

Poprečni profil magistralnog puta se sastoji od ukupno dvije saobraćajne trake, odnosno sa po jednom trakom za svaki smjer, dok je poprečni profil transferzale T8 od ukupno pet traka, dvije po smjeru i jedna za lijeva skretanja u zoni raskrsnice. [1]

\section{ELEMENTI PLANA I PROFILA PO VARIJANTAMA}

\begin{tabular}{|c|c|c|c|}
\hline & Varijanta 1 & Varijanta 2 & Varijanta 3 \\
\hline Kružni tok & - & - & \\
\hline Vanjski radijus $(m)$ & - & - & 28.5 \\
\hline Unutrašnji radijus (m) & - & - & 17 \\
\hline Širina kolovoza (m) & - & - & 10 \\
\hline Širina Aprona (m) & - & - & 1.5 \\
\hline \multicolumn{4}{|l|}{ Krak 1 -M4 zapad } \\
\hline Dužina $(m)$ & 540 & 180 & 101 \\
\hline Širina kolovoza (m) & 14 & 7 & 8.1 \\
\hline Širina ulaza $(m)$ & - & - & 4 \\
\hline Širina izlaza (m) & - & - & 5 \\
\hline Ulazni radijus $(\mathrm{m})$ & - & - & 14.5 \\
\hline Izlazni radijus $(\mathrm{m})$ & & & 19.5 \\
\hline $\begin{array}{l}\text { Ostrvo (dužina } x \text { širina na } \\
\text { kraju) }\end{array}$ & $\begin{array}{c}\text { Ostrvo čitavom } \\
\text { dužinom } 1.5 \mathrm{~m} \text { širine }\end{array}$ & & $23 \times 5.5$ \\
\hline Dužina nadvožnjaka (m) & 24 & 21 & \\
\hline \multicolumn{4}{|l|}{ Krak 2 -M4 istok } \\
\hline Dužina (m) & 177 & 170 & 50 \\
\hline Širina kolovoza (m) & 14 & 7 & 7.4 \\
\hline Širina ulaza (m) & - & - & 4 \\
\hline Širina izlaza (m) & - & - & 5 \\
\hline Ulazni radijus $(m)$ & - & - & 14.5 \\
\hline Izlazni radijus $(m)$ & - & - & 19.5 \\
\hline $\begin{array}{l}\text { Ostrvo (dužina } x \text { širina na } \\
\text { kraju) }\end{array}$ & $\begin{array}{c}\text { Ostrvo čitavom } \\
\text { dužinom } 1.5 \mathrm{~m} \text { širine }\end{array}$ & - & $16.5 \times 4.5$ \\
\hline \multicolumn{4}{|l|}{ Krak 3 - T8 jug } \\
\hline Dužina (m) & 307 & 242 & 40 \\
\hline Širina kolovoza (m) & 14 & 7 & 17.1 \\
\hline Širina ulaza (m) & - & - & 8 \\
\hline Širina izlaza (m) & - & - & 9 \\
\hline
\end{tabular}




\section{$5^{\text {th }}$}

INTERNATIONAL CONFERENCE

Contemporary achievements in civil engineering 21. April 2017. Subotica, SERBIA

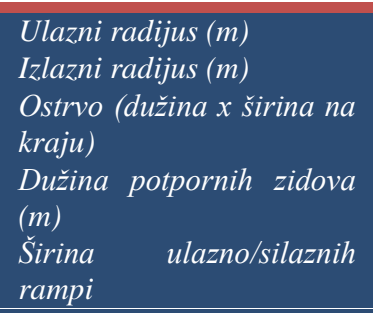

Površina kolovoza (m2)

Površina trotoara (m2)

Površina zelenila (m2)

Površina ostrva (m2)

Površina aprona (m2)

Dužina potpornih zidova

(m)

Dužina nadvožnjaka (m)

\begin{tabular}{|c|c|c|}
\hline- & - & 19.5 \\
\hline- & - & 24.5 \\
\hline $\begin{array}{c}\text { Ostrvo čitavom } \\
\text { dužinom } 2 \mathrm{~m} \text { širine }\end{array}$ & $\begin{array}{c}\text { Ostrvo čitavom } \\
\text { dužinom } 2 \mathrm{~m} \text { širine }\end{array}$ & $\begin{array}{c}\text { Ostrvo čitavom } \\
\text { dužinom }\end{array}$ \\
\hline- & 80 & - \\
\hline $4.5 / 4.5$ & & - \\
\hline Varijanta 1 & $4.5 ; 3.5 / 3.5$ & \\
\hline 15976 & Varijanta 2 & Varijanta 3 \\
\hline 3980 & 8115 & 3666 \\
\hline 1395 & 2741 & 1086 \\
\hline- & - & 908 \\
\hline- & & 186 \\
\hline 140 & - & 167 \\
\hline 24 & & - \\
\hline
\end{tabular}

Tabela 1. Elementi plana i profila

\section{ANALIZA NIVOA USLUGE}

Analizom nivoa usluge obuhvaćene su tri varijante raskrsnice. Za analizu je korišten aplikativni softver iz oblasti saobraćajnog inženjerstva Synchro v8.0 koji je prilagođen metodologiji HCM -a 2010 (Highway Capacity Manual). [2]

HCM Unsignalized Intersection Capacity Analysis

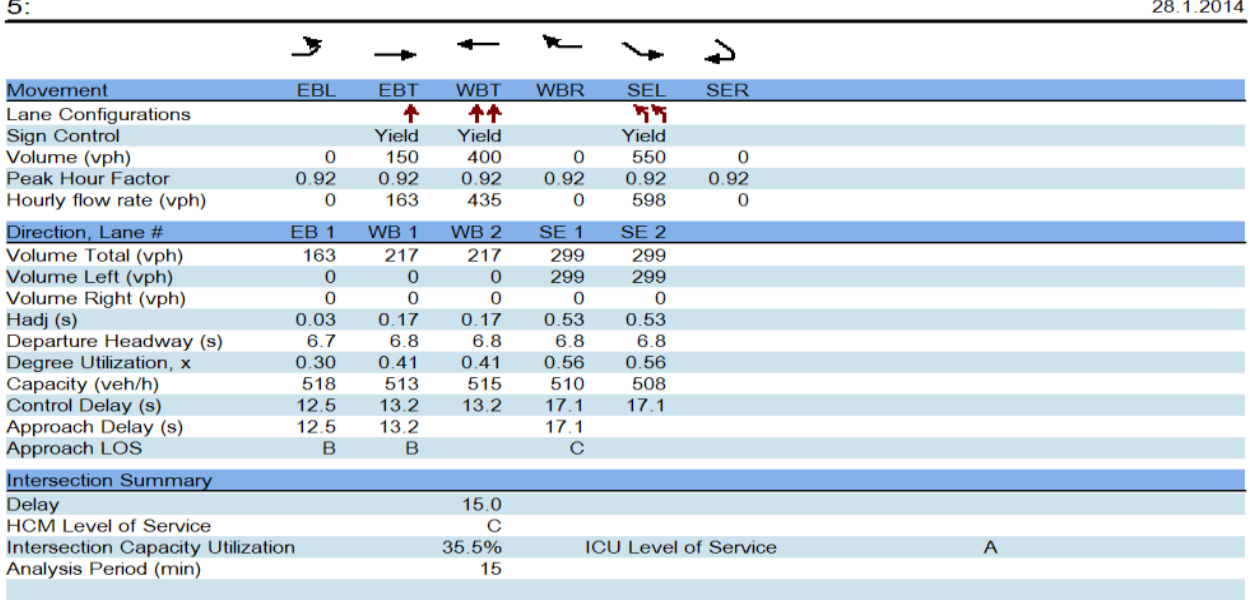

Slika 1. Izvještaj iz programa Synchro 8. sa proračunatim nivoom usluge za varijantu 1. 
Prilikom analiziranja Varijanti 1 i 2, gdje se planira produžetak Transverzale 8 na sjever, veličine saobraćajnih tokova sa sjevernog prilaza su aproksimirane na osnovu ranije izvršenih brojanja na susjednim raskrsnicama, te na osnovu prethodnih planerskih iskustava u gradovima veličine kao što je Grad Tuzla.

Varijanta 1. je definisana na planiranoj rekonstrukciji magistralne ceste M4 na ovoj dionici, s obzirom da se ista nalazi u horizontalnoj krivini. Rekonstrukcijom magistralnog puta M4 predviđa se nadogradnja dvije saobraćajne trake i korekcija elemenata horizontalne geometrije kao i nivelete u dužini od $800 \mathrm{~m}$. Transferzala T8 bi sa svijetlom visinom od $4,50 \mathrm{~m}$ prolazila ispod rekonstruisanog magistralnog puta M4, odnosno, magistralni put bi prelazio nadvožnjakom preko pomenute raskrsnice. Veza denivelisanih saobraćajnica bila bi omogućena izgradnjom dvije rampe jedna uzlazno-silazna, i jedna uzlazna. [1]

Preliminarnom analizom varijante raskrsnice utvrđena je iskorištenost kapaciteta od $35.5 \%$ i nivo usluge za varijantu 1 je $C$. [2]

Varijanta 2. je definisana na istom konceptu kao i varijanta 1, ali bez dodatnih intervencija na magistralnom putu M4 izuzev korekcija koje se odnose na obezbjeđenje neophodne visine svijetlog otvora između denivelisanih saobraćajnica. Takođe, veza T8 i M4 se ostvaruje izgradnjom dvije rampe jedna silazna i jedna uzlazna kao i preko rekonstruisane dvosmjerne ceste na sjevernoj strani. [1]

Lanes, Volumes, Timings

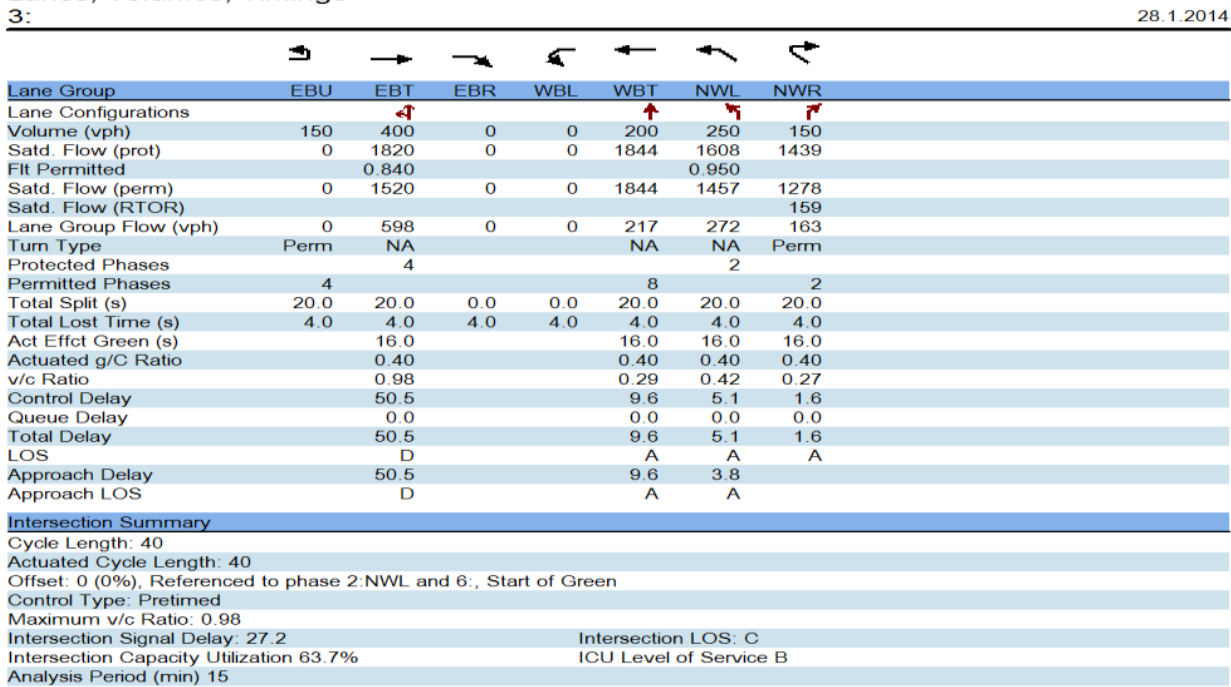

Slika 2. Izvještaj iz programa Synchro 8 , sa proračunatim nivoom usluge za varijantu 2.

Preliminarnom analizom varijante raskrsnice utvrđena je iskorištenost kapaciteta od $63.7 \%$ i nivo usluge za varijantu 2 je C. [2] 
Contemporary achievements in civil engineering 21. April 2017. Subotica, SERBIA

Varijanta 3. je definisana kao dvotračna kružna raskrsnica sa jednotračnim ulazima/ izlazima širine 4/5 metara na magistralnom putu M4, i dvotračnim ulazima/izlazima širine 4/5 metara sa zadržavanjem središnjeg ostrva na dijelu transferzale T8 jer se na ovaj način ne ugrožava komforan poprečni profil trasnferzale. Horizontalna geometrija je projektovana kako bi se zadovoljila prohodnost mjerodavnog vozila. Kružni tok je spušten južno po pravcu transferzale T8 kako bi se dobio odgovarajući prostor, kao i da bi se izbjegli problemi sa uklapanjem u postojeće stanje tj. da se ne bi ugrozili stambeni objekti sa sjeverne strane. [1]

Lanes, Volumes, Timings

1: Transverzala 8 \& M4-ka centru/M4-ka S.Hanu 28.1.2014

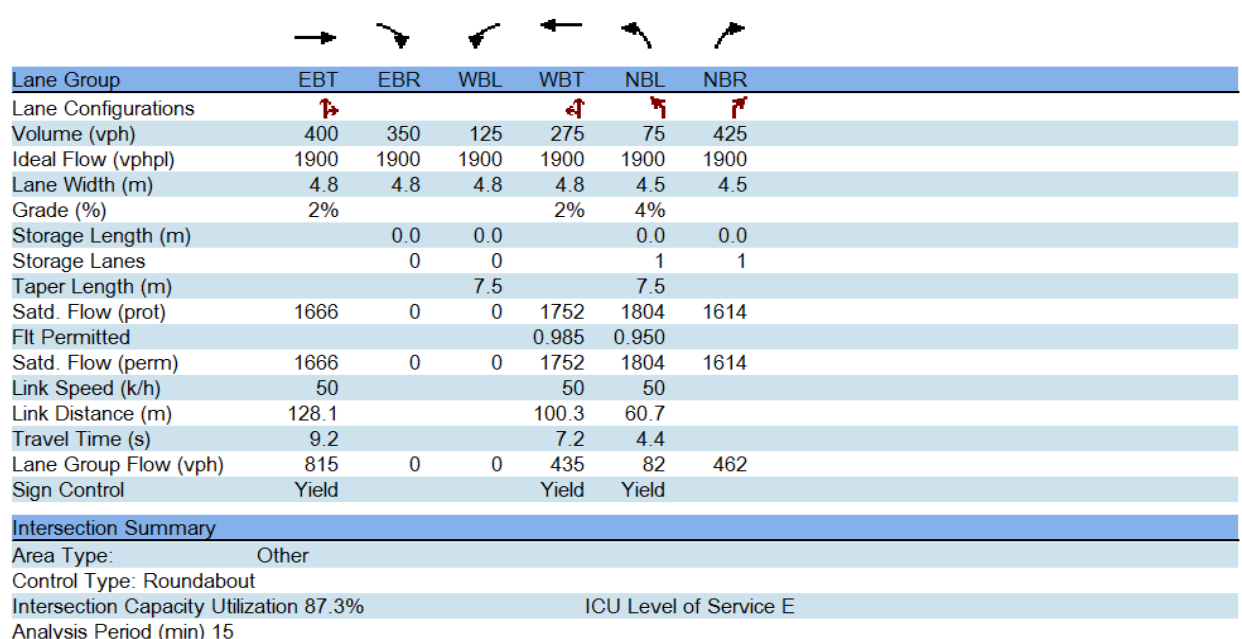

Slika 3. Izvještaj iz programa Synchro 8 , sa proračunatim nivoom usluge za varijantu 3

Preliminarnom analizom varijante 3 - kružna raskrsnica utvrđena je iskorištenost kapaciteta od $87.3 \%$ i nivo usluge za varijantu 3 je E. [2]

\section{TROŠKOVI EKSPROPRIJACIJE I TROŠKOVI GRAĐENJA}

\begin{tabular}{|c|c|c|c|}
\hline & VARIJANTA 1 & VARIJANTA 2 & VARIJANTA 3 \\
\hline $\begin{array}{l}\text { UKUPNA } \\
P O V R S ̌ N A \quad Z A \\
I Z U Z I M A N J E(m 2)\end{array}$ & 15937,3 & 7983 & 3579,60 \\
\hline 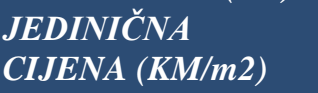 & 20 & 20 & 20 \\
\hline UKUPNA CIJENA & 318746 & 159660 & 71592 \\
\hline
\end{tabular}


5.

МЕЂУНАРОДНА КОНФЕРЕНЦИЈА

Савремена достигнућа у грађевинарству 21. април 2017. Суботица, СРБИЈА

\begin{tabular}{|c|c|c|c|}
\hline BROJ PARCELA & 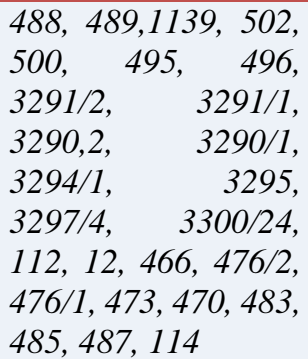 & $\begin{array}{l}488,485, \quad 487, \\
466,112,12,494, \\
114\end{array}$ & 488 \\
\hline
\end{tabular}

Tabela 2. Ukupna cijena eksproprijacije

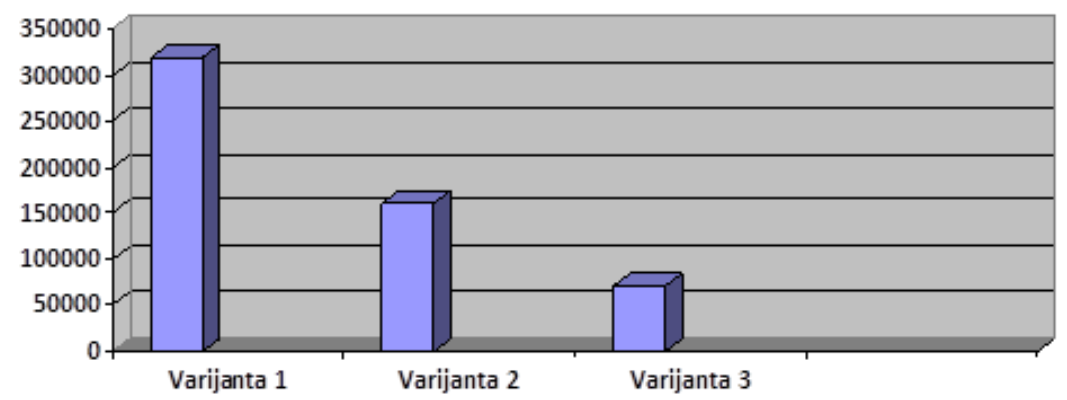

Slika 4. Grafički prikaz cijena eksproprijacije

\section{PRIKAZ I UPOREĐIVANJE RAZMATRANIH VARIJANTI}

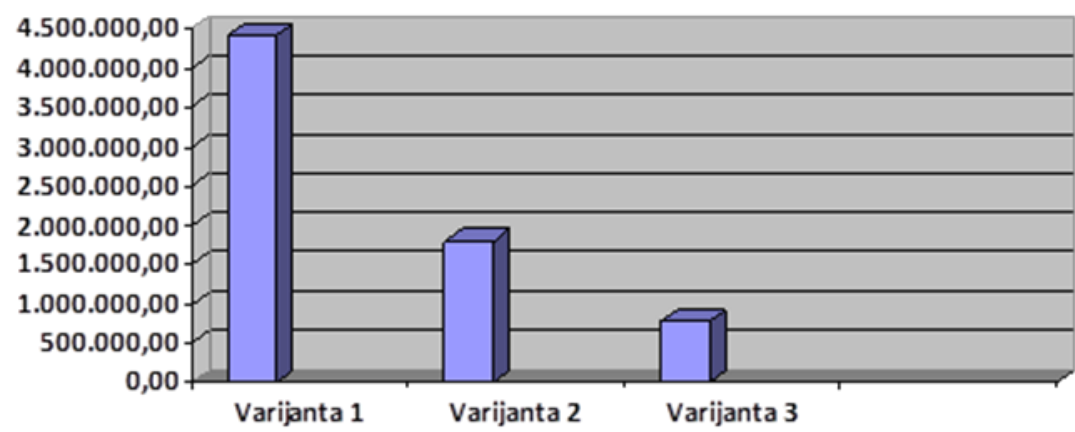

Slika 5. Grafički prikaz ukupne cijene građenja 
Contemporary achievements in civil engineering 21. April 2017. Subotica, SERBIA

\section{ZAKLJUČAK}

Radom su prezentovana varijantna rješenja gradske saobraćajnice na spoju magistralne ceste M4 i transferzale T8 u Tuzli.

Prikazani su i razrađeni elementi plana i elementi profila po varijantama kao i troškovi građenja uključujući i troškove eksproprijacije.

Isto tako urađena je i analiza nivoa usluge za varijantna rješenja raskrsnice. Za analizu je korišten aplikativni softver iz oblasti saobraćajnog inženjerstva Synchro v8.0 koji je prilogođen metodologiji HCM -a 2010 (Highway Capacity Manual).

Prilikom analiziranja i traženja optimanog rješenja raskrsnice na spoju magistralne ceste M4 i transferzale T8 u Tuzli, za svaku od varijanti je urađen i predmjer radova sa uključenim cijenama radova i radne snage kako bi svi elementi koji utiču na konačan izbor optimalne varijante bili uključeni.

$\mathrm{Na}$ osnovu višekriterijumske analize razmatranih varijanti, usvojena je varijana 1 kao optimalno tehničko rješenje. Iako najskuplja, varijanta 1 predstavlja nasloženiji i najobiminiji tehnički poduhvat od priloženih varijanti, ali sa aspekta društvenog interesa kao i po pitanju sinhronizacija sa prostorno planskim rješenjima koje Grad Tuzla planira da realizuje, ova varijanta predstavlja optimalan koncept.

Rad predstavlja osnovu za daljnja istraživanja i može poslužiti kao dobra osnova za rješavanje problematike vezane za gradske saobrćajnice i raskrsnice.

\section{LITERATURA}

[1] IDEJNI PROJEKAT NASTAVKA „JUŽNE SAOBRAĆAJNICE“ U TUZLI, DIONICA ŠI SELO - SLAVINOVIĆI, L=cca $1 \mathrm{KM}$, Institut za građevinarstvo „IG“ d.o.o. Banja Luka, 2014.

[2] Synchro Studio 8, Warrants 8, \& TripGen 2013.,Version 8 (Updated December 18, 2014)

[3] Topologija gradskih saobraćajnica, Nadzor i regulisanje cestovnog saobraćaja, Fakultet za Saobracaj i Komunikacije, Sarajevo 2013.

[4] Autorizovana predavanja Dr. sc. Zahid Bašić, Gradske saobraćajnice i raskrsnice, Univerzitet u Tuzli, Tuzla 2015.

\section{ANALYSIS AND COMPARISON OF ALTERNATIVES CITY CROSSROADS IN TUZLA}

Summary: This work presents alternative solutions city road at the junction of the main road M4 and transversal T8 in Tuzla.

Option 1, is defined by the planned reconstruction of the main road M4 at this stage, given that it is located in a horizontal curve. The reconstruction of the main road M4 predicted upgrade two traffic lanes and correction elements horizontal geometry and the vertical alignment over a length of $800 \mathrm{~m}$. Transversal to T8 with bright height of $4.50 \mathrm{~m}$ passing beneath the reconstructed highway M4, respectively, the main road to crossing the 
Савремена достигнућа у грађевинарству 21. април 2017. Суботица, СРБИЈА

overpass over the mentioned intersection. Connection leveled roads would be enabled by building two ramps one ascending-descending, and one upward. Option 2, is defined on the same concept as the variant 1, but without further intervention on the highway M4 except for corrections relating to the provision of the necessary clear height between grade separated junctions. Also, the connection T8 and M4 is achieved by building two ramps one downward and one upward and over the reconstructed two-way road on the north side. Option 3, is defined as a two-lane roundabout with a single-lane entryway loutputs width of 4.5 meters on the main road M4, and two-lane entryway loutputs width of 5.4 meters with the retention of the central islands of the transversal T8 because in this way does not compromise comfort cross section trasnferzale. The horizontal geometry is designed to meet the mobility of the relevant vehicle. Round about is down south along the direction transversal 78 to obtain adequate space, as well as to avoid problems with fitting in the current situation, ie. so as not to jeopardize the residential buildings on the north side. The paper presents elements of the plan and profile elements by variants as well as construction costs including the cost of expropriation.

Keywords: highway, transversal, cross roads, flyover, roundabout 